\title{
AUDITORY AND HEAD-UP DISPLAYS FOR ECO-DRIVING INTERFACES
}

Woodbury Shortridge

Sonification Lab, Georgia Institute of Technology, 654 Cherry Street, Atlanta, GA, 30332, USA whshortridge@gmail.com

Brittany E. Noah

Sonification Lab, Georgia Institute of Technology, 654 Cherry Street, Atlanta, GA, 30332, USA brittany.noah@gatech.edu

\section{ABSTRACT}

Eco-driving describes a strategy for operating a vehicle in a fuel-efficient manner. Current research shows that visual ecodriving interfaces can reduce fuel consumption by shaping motorists' driving behavior but may hinder safe driving performance. The present study aimed to generate insights and direction for design iterations of auditory eco-driving displays and a potential matching head-up visual display to minimize the negative effects of using purely visual headdown eco-driving displays. Experiment 1 used a sound cardsorting task to establish mapping, scaling, and polarity of acoustic parameters for auditory eco-driving interfaces. Surveys following each sorting task determined preferences for the auditory display types. Experiment 2 was a sorting task to investigate design parameters of visual icons that are to be paired with these auditory displays. Surveys following each task revealed preferences for the displays. The results facilitated the design of intuitive interface prototypes for an auditory and matching head-up eco-driving display that can be compared to each other.

\section{INTRODUCTION}

From 1990 to 2007 transportation has been responsible for a $45 \%$ growth in $\mathrm{CO}_{2}$ emissions, with a predicted rise of an additional $40 \%$ by 2030 [1]. Emerging innovations in vehicles are aimed at improving fuel economy (FE) to reduce emissions and reduce cost of ownership. Saving fuel can immediately reduce cost of operation and environmental impacts. Eco-driving is a readily available technique that shapes driving behaviors increase FE without reliance on automotive advances such as body or engine changes. Research shows that driving styles such as rapid acceleration and deceleration hinder eco-driving; and therefore, are used as prompts for eco-driving displays [2].

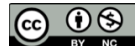

This work is licensed under Creative Commons Attribution - Non Commercial 4.0 International License.

The full terms of the License are available at

http://creativecommons.org/licenses/by-nc/4.0/

\author{
Thomas M. Gable
}

Sonification Lab, Georgia Institute of Technology, 654 Cherry Street, Atlanta, GA, 30332, USA thomas.gable@gatech.edu

\section{Bruce N. Walker}

Sonification Lab, Georgia Institute of Technology, 654 Cherry Street, Atlanta, GA, 30332, USA bruce.walker@psych.gatech.edu

Herein we discuss efforts to develop low workload displays for eco-driving, notably, through auditory displays and visual head-up displays.

\section{Current Eco-Driving Interfaces}

Fuel Economy Driver Interfaces (FEDIs) have been shown to improve FE by up to $20 \%$ [3]. However, nearly all research and development of FEDIs has focused on visual displays [4], with most being head-down, dashboard displays. Figure 1 shows the TOYOTA Eco-Indicator, an eco-indicator bar that tells you how economically you are driving. When the driver is accelerating excessively, the bar will stretch beyond the "eco zone" and start flashing. That means it is likely that more fuel than needed is being used. Unfortunately, driving is a demanding task when it comes to visual attention [5] and since most current FEDIs also rely on visual resources, this may create a competition for additional resources. Evidence supports the case that current visual FEDIs can distract drivers from attending to the road, increase workload, and in effect, hinder driving performance [4].

\subsection{Design Considerations}

While current dashboard-based FEDIs may increase distraction, there are other approaches to design eco-driving interfaces that limit driver distraction while simultaneously shaping motorists' driving behaviors. In order to increase driver safety and FE, head-up displays (HUDs) and auditory displays should be explored.

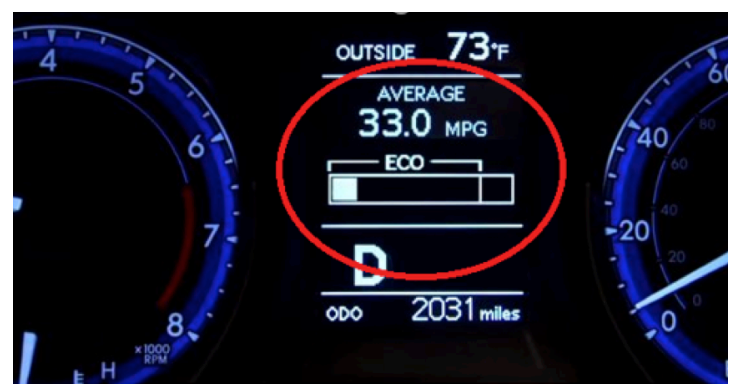

Figure 1: The TOYOTA Eco-Indicator: A visual-only dashboard display of fuel economy. 


\subsubsection{Auditory Displays}

Wickens' Multiple Resource Theory (MRT) [6] provides valuable insights for this investigation. This multitasking theory proposes that the limited capacity of working memory creates a bottleneck when resources are exhausted [7]. The bottleneck leads to a reduction in working memory resources for a primary task, when a secondary task of the same modality is introduced. As Wickens [6] suggests, when such homogeneous tasks are imposed, performance declines due to mental workload overload. For example, a visual display on a car stereo (a secondary task) may limit the resources available for the visual needs of the (primary) driving task. The theory suggests that in this instance, secondary tasks should be done via a different modality [6]. One potential modality in this case is the auditory modality.

Auditory displays for In-Car Infotainment Systems (ICIS) have been shown to increase a driver's visual attention on the primary driving task (driving), as compared to visual invehicle displays [8]. Results from a driving simulator and eye-tracking experiment showed sonification assistance, with respect to the ICIS, significantly reduced eye-movements towards the ICIS, thereby reducing participants' reaction times in the primary driving task. This finding corroborates the multiple resource theory model of multitasking by enhancing driving performance with reduced visual tasking [8]. Previous research has also resulted in similar conclusions for interfaces that used sound within the vehicle context, including increased visual attention on the driving task [9] and better driving performance [10].

While no audio-only FEDI is found in the literature or commercially, a FEDI including complimentary audio to a visual display has been studied [4]. That prototype multimodal display included a lower frequency tone $(512 \mathrm{~Hz})$ to indicate insufficient acceleration and a higher frequency tone (predominantly at $1770 \mathrm{~Hz}$ ) to indicate excessive acceleration. Preferences revealed that participants tend to report displays with complementary audio as more effective at advising eco-driving behavior than visual-only displays [4]. In addition, behavioral measures showed that time spent looking at the road increased and drivers' pedal error (having the pedal outside the ideal range) decreased when using a system with added audio [4].

Unlike visual displays, auditory displays have the added capability to convey information to the driver, regardless of head or body position [11]. Auditory displays also allow for a wide range of information to be communicated to a driver through many dynamic acoustic parameters (in addition to speech sounds): frequency, timbre, range, register, and rhythm [11]. As Nees and Walker [12] suggest, an empirical investigation could determine the best mapping, scaling, and polarity of such sound features for a FEDI. Mapping, scaling, and polarity must be optimized to ensure that workload is not increased as a result of added auditory displays [13]. Further, driving performance and workload can be affected by annoyance [13]. When mapping acoustic parameters, it is important to consider trade-offs involving the effect of annoyance associated with some sounds [12].

\subsubsection{HUDs}

In-vehicle visual displays inherently demand more visual scanning time, thereby increasing cognitive load and distracting users from the driving task [14]. Empirical research has emphasized the importance of visual display placement in vehicles. The lower a display is positioned vertically (i.e., the farther below the windshield it is), the more severely driving performance is decreased, seen through increased reaction time and decreased target detection performance [15]. However, lane position can be maintained, even when attention is focused on in-vehicle displays, if the distance from the display to the outside line of sight is minimal [16]. This finding suggests that drivers can learn to manage dual-task load using peripheral vision, allowing them to maintain lane performance. Therefore, issues experienced using traditional visual displays may be overcome using head-up displays (HUD), which project information onto the vehicle windshield [17].

Simulator studies found that under both low- and highdifficulty driving conditions, drivers exhibit faster reaction times to task-related detection, such as speed limit sign changes, while attention is focused on the HUD [18]. Driving performance measures, such as variance of lateral acceleration, steering wheel turning (degrees), and acceleration are also improved while attending to the HUD as opposed to traditional head-down displays [18].

When designing HUDs, it is important to consider the trade-off between too much clutter and scanning-time cost. If too much information is displayed in the HUD, far-field vision becomes compromised and may cause attentional tunneling, which will decrease driving performance [19]. Therefore, it is recommended that the visual design reduce clutter by only including information that is pertinent to the task. As with all displays, ill-informed HUD designs could add to distraction, increased workload, and confusion [17]. Likewise, it is important to investigate the best mapping, scaling, and polarity of HUD designs to ensure the visual displays match a user's mental model of the system [20].

The amount of information communicated through visual displays has been studied in the context of FEDIs. A comparison of three different visual designs found that displays with greater information content were judged as more supportive for eco-driving behavior [4]. In that study a "foot-and-pedal" display showed current pedal error; a gauge display showed the rate of change of pedal error; and a dot display showed pedal error only. Results from behavior tests revealed speed maintenance with the gauge display was better than with the foot, whereas acceleration performance was better with the foot than with the gauge.

\section{THE CURRENT RESEARCH}

The primary goal of this study is to find patterns and preferences in the results that aid both auditory and HUD design decisions for future displays. The design guidance and prototypes this study yields for future research could result in advancements for both FE and driver safety. The present study suggests current visual heads-down eco-driving interfaces impose an additional visual demand to the already visually heavy task of driving. Although Young, Birrell, and Stanton [14] called for the development of eco-driving displays that decrease visual distraction, few examples of such research exist. There is a need to investigate the design of in-vehicle auditory and HUD displays that safely communicate how driver behavior affects fuel efficiency [2].

\subsection{Types of Displays}

\subsubsection{Types of information displayed}

There are two non-mutually exclusive categories of information that the displays in this study fall under: continuous and intermittent, and inform and instruct. 


\subsubsection{Continuous and Intermittent Displays}

The optimal temporal structure of a display system is an important aspect of design. In a recent study of truck drivers' preference regarding visual FEDIs, both continuous and intermittent display prototypes were tested in a simulator [21] Participants showed unique preferences for continuous and intermittent display types alike. A majority of participants noted that speed guidance (continuous display) was useful, easy to understand, and made controlling speed easier. A majority also found the performance feedback (intermittent display) positive, liking the feedback as an incentive to drive "eco-friendlier" [21]. In terms of an auditory display, a constant or continuous sound representing FE may generate annoyance [12]. Therefore, the current study assesses the best design parameters to be used in both a continuous and an intermittent display type for each modality (visual and auditory). For the purpose of this study, intermittent displays are designed to communicate the overall $\mathrm{FE}$ of a driving trip. In contrast, continuous displays are designed to give dynamic information about the current fuel economy.

\subsubsection{Inform and Instruct Displays}

In both the auditory and visual domain, this study proposes two primary display types for conveying information to the operator: inform and instruct displays.

Inform displays present information about a user's current behavior, increasing situation awareness to their current performance, allowing them to shape their behaviors to fit the task goals. In the current research domain, such a display might tell the driver if he or she is accelerating too fast or too slowly to meet the eco-driving goals.

On the other hand, instruct displays directly communicate how the user should change their behavior to accomplish the task goals. This means that users do not need to use this information to compare to the goal state but are instead told exactly what to do. So, for someone trying to increase their fuel economy an instruct display might tell a driver to accelerate more slowly.

Previous research has investigated a similar concept, finding that displays presenting more persuasive information (displays focused on convincing the user to change their behavior) were perceived as less useful and more difficult [22]. The instruct displays in this study (i.e., telling drivers how to behave), are analogous to those persuasive displays.

\subsection{Experiment 1 (Auditory Matching) Overview}

This participatory design study iteratively investigated sound parameters for the design of an auditory eco-driving interface. Sound-sorting methods provide an efficient way to categorize and evaluate sound design parameters, especially when there is a large number of stimuli $[11,23]$. Participants matched sound parameters to eco-driving icons and descriptions. Participants completed a forced choice matching task with three sections (one for each display type): inform, instruct, and overall FE. Inform and instruct eco-driving concepts were investigated as continuous methods of display, whereas overall FE was an intermittent display. The frequency data collected through the number of times a sound was matched with a description of an eco-driving behavior established acoustic mappings, scaling, and polarity for each type of ecodriving display. In addition, a survey after each section of the forced choice task determined preferences for display types.

With the results of Experiment 1, the auditory design process took into account certain capabilities and limitations of sound characteristics inside the vehicle. A key limitation in vehicles is acoustic masking related to vehicle and road noise [12]. Experiment 1 results and special acoustic considerations facilitated the design of an intuitive and unambiguous auditory interface prototype to be used in future driving simulator research.

\subsection{Experiment 2 (Visual Matching) Overview}

This participatory design study investigated visual parameters for an iterative design of a HUD eco-driving interface. Card-sorting methods were also used as a way to categorize and evaluate visual designs. In the card-sorting, visual icons were matched to eco-driving words or concepts. There were three forced-choice matching tasks: instruct, inform, and overall FE. The frequency data collected through the number of times a sound was matched with a description of an eco-driving behavior established mappings, scaling, and polarity for each type of eco-driving display. Again, a survey following each task determined preferences for each type of display: instruct, inform, and overall FE.

In addition to the Experiment 2 data, the HUD design process took into account special visual design considerations, such as compromising far-field vision and attentional tunneling [17]. Experiment 2 results and special design considerations facilitated the design of an intuitive and usable HUD prototype for future driving research.

\subsection{Research Questions and Hypotheses}

Research Question 1: Which acoustic parameters are most useful and preferred for an auditory display of eco-driving concepts?

Research Question 2: Which visual parameters are most useful and preferred for a HUD of eco-driving concepts?

Hypothesis 1: Participants will display a higher preference for inform compared to instruct displays.

\section{EXPERIMENT 1}

\subsection{Participants}

Participants included 41 students (19 male) with an average age of 20.2 years $(\mathrm{SD}=1.8)$. Participants were required to be 18 or older to ensure they had some driving experience and were required to have normal or corrected to normal vision and hearing to control for abilities needed to perform the sound card-sorting task. They held a driver's license for an average of 3.7 years $(\mathrm{SD}=2.0)$.

\subsection{Materials}

The sound-sorting program used in the current study was written using HTML, jQuery, and Bootstrap's framework. Using Ableton Live music production software, sounds themselves were designed for acoustic parameters of interest. Surveys were constructed and executed online. Sounds were heard through SONY MDR-V150 Dynamic Stereo Headphones.

Three types of auditory displays were used in the study: earcons, auditory icons, and speech. Earcons are abstract sounds with no prior association (e.g., musical phrases), but the matching frequencies were expected to yield relationships between acoustic parameters and perceptions of constructs $[11,23]$. Auditory icons are sounds that are ecologically associated (e.g., engine noises), and speech consisted of textto-speech generations [12]. 


\subsection{Procedure}

Upon arrival participants signed consent forms and then sat at a computer, put on headphones, and began the soundsorting program. The program started with a tutorial so that participants could become accustomed to the drag-and-drop procedure used to sort sounds.

There were three within-subject trials: one each for informational, instructional, and overall FE displays. The independent variables were the acoustic parameters presented on each slide: ADSR (attack, decay, sustain, release), audio effects, instruments (timbre), auditory icons, triads (musical chords), voices, scales (speech), register (musical octaves), range (distance between frequencies), and tempos. Sound parameters varied randomly within each trial. The first and second trials were randomly assigned. These trials investigated acoustic parameters for a continuous display. One trial asked participants to match sounds to driving instruction icon-word pairs, shown in Figure 2. Second, sounds were matched to icon-word pairs that inform a driver of current driving behavior status. A third trial investigated acoustic parameters for an intermittent display by having participants match sounds to a metric of overall FE.

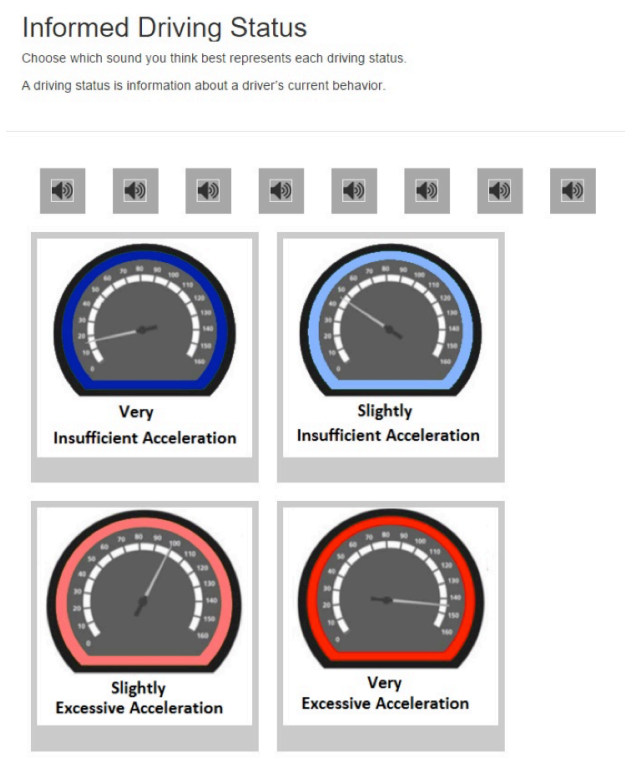

\section{gure 2: Inform display trial from Experiment 1.}

Next, a survey asked participants which type of auditory displays (earcons, auditory icons, or speech) they believe to be most informative, least distracting, and would prefer. After both trials one and two were completed, there was an additional survey assessing user preference for an inform versus an instruct display. Following the third trial, a survey asked participants which type of overall FE display they believed to be most informative, least distracting, and would prefer: earcons, auditory icons, speech, earcons and speech, or auditory icons and speech.

\subsection{Results}

\subsubsection{Sound card sorting results}

Frequencies and percentages for sound-to-concept matches were calculated for the various acoustic parameters in each category. Due to the exploratory nature of the study, frequency counts were found to be the most useful type of data. Not all acoustic parameters resulted in high matching agreement between participants, but for some there were clear trends. As seen in Figure 3, there was high agreement among listeners that a musical phrase starting at note $\mathrm{C} 0$ and ascending to note $\mathrm{C} 5$ matched best to the concept of accelerate a lot, whereas a descending phrase from note $\mathrm{C} 5$ to $\mathrm{C} 0$ matched best to the concept of decelerate a lot. Similarly, $\mathrm{C} 1$ ascending to $\mathrm{C} 4$ and $\mathrm{C} 2$ to $\mathrm{C} 3$, matched best to accelerate a little, whereas $\mathrm{C} 3$ descending to $\mathrm{C} 2$ and $\mathrm{C} 4$ to $\mathrm{C} 1$ matched best to decelerate a little. The trend found in this particular set of sounds reveals auditory design guidance: an accelerate instruction is best matched to an increasing frequency; a decelerate instruction is best matched to a decreasing frequency; and range (distance between notes) can represent the magnitude of change in acceleration instructions. Using frequencies recorded in the three trials, an equivalent analysis was conducted for each acoustic parameter and auditory display studied: ADSR, audio effects, instruments, auditory icons, triads, voices, scales, register, range, and tempos. High matching agreement was determined and recorded (Table 1).

\begin{tabular}{|c|c|c|c|}
\hline & Instruct & Inform & Overall Eco Preformance \\
\hline \multirow{4}{*}{ ADSR } & Accelerate & Insufficient Acceleration & Low Fuel Economy \\
\hline & Slow Attack, High Sustain & Fast Attack, Low Sustain & High Sustain \\
\hline & Decelerate & Excessive Acceleration & High Fuel Economy \\
\hline & Fast Attack, Low Sustain & High Sustain & Fast Attack \\
\hline \multirow{4}{*}{ Effects } & Accelerate & Insufficient Acceleration & Low Fuel Economy \\
\hline & High Freq. EQ & Reverb, Low Freq. EQ & Delay, Reverb \\
\hline & Decelerate & Excessive Acceleration & High Fuel Economy \\
\hline & Low Freq. EQ, Delay & Delay, Distort & High Freq. EQ \\
\hline \multirow{4}{*}{$\begin{array}{l}\text { Instru- } \\
\text { ments }\end{array}$} & Accelerate & Insufficient Acceleration & Low Fuel Economy \\
\hline & String, Xylophone & Bass & Brass, Marimba \\
\hline & Decelerate & Excessive Acceleration & High Fuel Economy \\
\hline & Bass, Marimba & Brass & Xylophone \\
\hline \multirow{4}{*}{ Icons } & Accelerate & Insufficient Acceleration & Low Fuel Economy \\
\hline & Engine Freq. Up & Engine Freq. Down & Short Guzzler \\
\hline & Decelerate & Excessive Acceleration & High Fuel Economy \\
\hline & Engine Freq. Down & Engine Freq. Up & Long Guzzler \\
\hline \multirow{4}{*}{ Triads } & Accelerate & Insufficient Acceleration & Low Fuel Economy \\
\hline & Major Ascending & Aug. \& Major Descending & Aug. \& Dim. Descending \\
\hline & Decelerate & Excessive Acceleration & High Fuel Economy \\
\hline & Minor Descending & Major \& Aug. Ascending & Major Ascending \\
\hline \multirow{4}{*}{ Voices } & Accelerate & Insufficient Acceleration & Low Fuel Economy \\
\hline & Female & Female & Female \\
\hline & Decelerate & Excessive Acceleration & High Fuel Economy \\
\hline & Male \& Female & Male \& Female & Female \\
\hline \multirow{4}{*}{ Scales } & Accelerate & Insufficient Acceleration & Low Fuel Economy \\
\hline & Major \& Minor Ascending & Major Descending & Minor \& Blues Descending \\
\hline & Decelerate & Excessive Acceleration & High Fuel Economy \\
\hline & Major \& Minor Descending & Minor Ascending & Major \& Minor Ascending \\
\hline \multirow{4}{*}{ Registe } & Accelerate & Insufficient Acceleration & Low Fuel Economy \\
\hline & $\mathrm{C} 4>\mathrm{C} 3>\mathrm{C} 2$ & $\mathrm{C} 2>\mathrm{C} 3>\mathrm{C} 4$ & $\mathrm{C} 2>\mathrm{C} 3>\mathrm{C} 4$ \\
\hline & Decelerate & Excessive Acceleration & High Fuel Economy \\
\hline & $\mathrm{C} 2>\mathrm{C} 3>\mathrm{C} 4$ & $\mathrm{C} 4>\mathrm{C} 3>\mathrm{C} 2$ & $\mathrm{C} 4>\mathrm{C} 3>\mathrm{C} 2$ \\
\hline \multirow{4}{*}{ Range } & Accelerate & Insufficient Acceleration & Low Fuel Economy \\
\hline & C0-C5 Ascending & C5-CO Descending & C5-CO Descending \\
\hline & Decelerate & Excessive Acceleration & High Fuel Economy \\
\hline & C5-C0 Descending & CO-C5 Ascending & CO-C5 Ascending \\
\hline \multirow{4}{*}{ Tempos } & Accelerate & Insufficient Acceleration & Low Fuel Economy \\
\hline & Fast, Increasing & Decreasing, Slow & Slow, Decreasing \\
\hline & Decelerate & Excessive Acceleration & High Fuel Economy \\
\hline & Decreasing, Slow & Increasing, Fast & Fast, Increasing \\
\hline
\end{tabular}

Table 1: Auditory parameters resulting in high matching agreement between participants. 


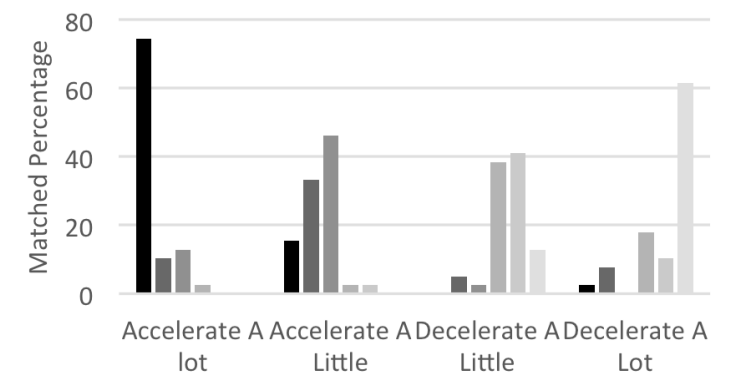

$\square$ C0 to C5 $\square$ C1 to C4 $\square$ C2 to C3 $\square$ C3 to C2 $\square$ C4 to C1 $\square$ C5 to C0

Figure 3: Match percentages of various ranges from Experiment 1 instruct trial.

\subsubsection{Survey results}

Response frequencies from the surveys following each trial show that auditory icons were generally reported as most distracting across all trials (see Table 2). The auditory icons were ecologically associated, meaning they resembled engine noises. This is compounded with acoustic masking and therefore, earcons and speech were considered best for an eco-driving auditory display. Participants were generally in agreement that speech was more informative than earcons in both the instruct and inform trials. However, there was no consensus as to which was preferred. In the overall FE trial, there was agreement that a display with both earcons and speech would be most informative and preferred.

Responses were higher for instruct displays over inform displays across all three measures. A chi square binomial probability test showed the instruct display had higher ease of understanding $(p=0.001)$. This means that in auditory FEDIs instruct information was preferred.

\begin{tabular}{|c|c|c|c|c|c|}
\hline Inform & \multicolumn{2}{|c|}{ Earcon } & \multicolumn{2}{|c|}{ Icon } & Voice \\
\hline Most Informative & \multicolumn{2}{|c|}{3} & \multicolumn{2}{|c|}{12} & 25 \\
\hline Least Distracting & \multicolumn{2}{|c|}{18} & \multicolumn{2}{|c|}{8} & 14 \\
\hline Most Preferred & \multicolumn{2}{|c|}{14} & \multicolumn{2}{|c|}{8} & 18 \\
\hline Instruct & \multicolumn{2}{|c|}{ Earcon } & \multicolumn{2}{|c|}{ Icon } & Voice \\
\hline Most Informative & \multicolumn{2}{|c|}{3} & \multicolumn{2}{|l|}{9} & 26 \\
\hline Least Distracting & \multicolumn{2}{|c|}{16} & \multicolumn{2}{|c|}{6} & 16 \\
\hline Most Preferred & \multicolumn{2}{|c|}{11} & \multicolumn{2}{|c|}{3} & 24 \\
\hline $\begin{array}{l}\text { Overall Eco- } \\
\text { Driving }\end{array}$ & Earcon & Icon & Voice & $\begin{array}{c}\text { Earcon \& } \\
\text { Voice }\end{array}$ & $\begin{array}{l}\text { Icon \& } \\
\text { Voice }\end{array}$ \\
\hline Most Informative & 4 & 2 & 8 & 19 & 6 \\
\hline Least Distracting & 12 & 7 & 9 & 8 & 3 \\
\hline Most Preferred & 8 & 1 & 8 & 15 & 7 \\
\hline Instruct vs Inform & \multicolumn{3}{|c|}{ Instruct } & \multicolumn{2}{|c|}{ Inform } \\
\hline Ease of Use & \multicolumn{3}{|c|}{30} & \multicolumn{2}{|c|}{10} \\
\hline Least Distracting & \multicolumn{3}{|c|}{22} & \multicolumn{2}{|c|}{18} \\
\hline Preference & \multicolumn{3}{|c|}{23} & \multicolumn{2}{|c|}{17} \\
\hline
\end{tabular}

Table 2: Preference survey frequencies from Experiment 1.

\section{EXPERIMENT 2}

\subsection{Participants}

Participants were 46 students (24 males) with an average of 20.1 years old $(\mathrm{SD}=1.7)$. Participants had the same age, vision, and hearing requirements as in Experiment 1 .
Participants had held a driver's license for an average of 3.3 years $(\mathrm{SD}=1.9)$.

\subsection{Procedure}

Participants sat at a computer and began the icon-sorting program, starting with a tutorial to become familiar with the procedure. Participants then matched each icon to an ecodriving concept by dragging and dropping.

There were three within-subject trials. The independent variables were the types of icons presented on each slide: vertical continuous bars, vertical segmented bars, horizontal continuous bars, horizontal segmented bars, arches, up-down arrows, forward-back arrows, colors, leaves, trees, and shoeon-pedal (Table 3 ). Images within each trial were randomly varied. The first and second trials were randomly assigned. These two trials investigated visual icons for a continuous display. One trial asked participants to match icons to driving instructions, as shown in Figure 4. In a second trial, icons were matched to words that inform a driver of current driving behavior status. The third trial investigated sound parameters for an intermittent display by asking participants to match sounds a metric of overall FE.

Following each of trials one and two, a survey asked participants which type of visual displays they believed to be most informative, least distracting, and would prefer as a user.

After both trials one and two were completed, there was an additional survey assessing user preference for an inform versus an instruct display. Subsequent to the third trial, a survey asked participants which type of overall FE display they believed to be most informative, least distracting, and would prefer as a user.

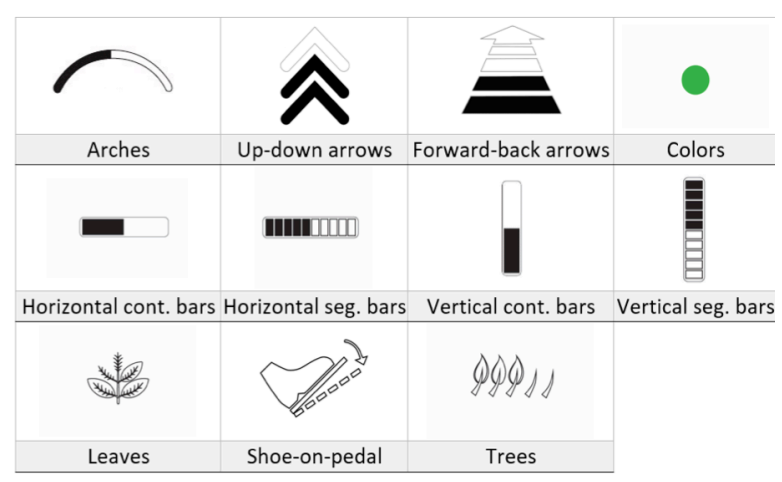

Table 3: An example of each type of image presented on the slides in Experiment 2.

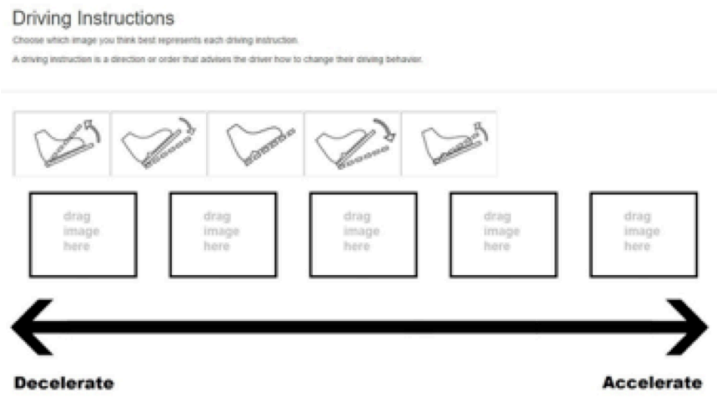

Figure 4: Instruct display trial from Experiment 2 


\subsection{Results}

5.3.1. Matching results

Frequencies and percentages for icons-to-concept matches were calculated for the various visual parameters in each category. It was not necessary to perform inferential statistical analyses because this study is exploratory in nature [23]. Most visual parameters did have high matching agreement between participants, indicating clear trends. As seen in Figure 5, there was high agreement among viewers that the color red matched best to the concept of decelerate a lot, the color orange matched best to the concept of decelerate a little, yellow matched best to appropriate

\begin{tabular}{|c|c|c|c|}
\hline & Instruct & Inform & $\begin{array}{l}\text { Overall Eco } \\
\text { Performance }\end{array}$ \\
\hline \multirow{4}{*}{$\begin{array}{l}\text { Vertical } \\
\text { Cont. Bars }\end{array}$} & & Insufficient Acceleration & Low Fuel Economy \\
\hline & & Down & Down \\
\hline & & Excessive Acceleration & High Fuel Economy \\
\hline & & Up & Up \\
\hline \multirow{4}{*}{$\begin{array}{l}\text { Vertical } \\
\text { Seg. Bars }\end{array}$} & Accelerate & Insufficient Acceleration & Low Fuel Economy \\
\hline & Up & Down & Down \\
\hline & Decelerate & Excessive Acceleration & High Fuel Economy \\
\hline & Down & Up & Up \\
\hline \multirow{4}{*}{$\begin{array}{l}\text { Horizontal } \\
\text { Cont. Bars }\end{array}$} & & Insufficient Acceleration & \\
\hline & & Left & \\
\hline & & Excessive Acceleration & \\
\hline & & Right & \\
\hline \multirow{4}{*}{$\begin{array}{l}\text { Horizontal } \\
\text { Seg. Bars }\end{array}$} & & Insufficient Acceleration & \\
\hline & & Left & \\
\hline & & Excessive Acceleration & \\
\hline & & Right & \\
\hline \multirow{4}{*}{ Arches } & & Insufficient Acceleration & \\
\hline & & Less fill & \\
\hline & & Excessive Acceleration & \\
\hline & & More fill & \\
\hline \multirow{4}{*}{$\begin{array}{c}\text { Arrows } \\
\text { (Forward/Back) }\end{array}$} & Accelerate & & \\
\hline & Forward & & \\
\hline & Decelerate & & \\
\hline & Back & & \\
\hline \multirow{4}{*}{$\begin{array}{c}\text { Arrows } \\
\text { (Forward/Back) }\end{array}$} & Accelerate & & \\
\hline & Forward & & \\
\hline & Decelerate & & \\
\hline & Back & & \\
\hline \multirow{4}{*}{$\begin{array}{c}\text { Arrows } \\
\text { (Up/Down) }\end{array}$} & Accelerate & & \\
\hline & Up & & \\
\hline & Decelerate & & \\
\hline & Down & & \\
\hline \multirow{4}{*}{ Colors } & Accelerate & Insufficient Acceleration & Low Fuel Economy \\
\hline & $\begin{array}{l}\text { Green>Light } \\
\text { Green }>\text { Yellow }\end{array}$ & \begin{tabular}{|l|} 
Green $>$ Light \\
Green $>$ Yellow
\end{tabular} & Red $>$ Orange $>$ Yellow \\
\hline & Decelerate & Excessive Acceleration & High Fuel Economy \\
\hline & Red $>$ Orange $>$ Yellow & Red $>$ Orange $>$ Yellow & $\begin{array}{l}\text { Green }>\text { Light } \\
\text { Green }>\text { Yellow }\end{array}$ \\
\hline \multirow{4}{*}{ Leaves } & & & Low Fuel Economy \\
\hline & & & Less leaves \\
\hline & & & High Fuel Economy \\
\hline & & & More leaves \\
\hline \multirow{4}{*}{ Trees } & & & Low Fuel Economy \\
\hline & & & Less trees \\
\hline & & & High Fuel Economy \\
\hline & & & More trees \\
\hline \multirow{4}{*}{ Shoes/Pedals } & Accelerate & & \\
\hline & Low angle & & \\
\hline & Decelerate & & \\
\hline & High angle & & \\
\hline
\end{tabular}

Table 4: Visual parameters resulting in high matching agreement between participants. acceleration, light green matched to accelerate a little, and dark green to accelerate a lot. Using frequencies recorded in all three trials, a similar analysis was conducted for each parameter and type of visual studied: vertical continuous bars, vertical segmented bars, horizontal continuous bars, horizontal segmented bars, arches, up-down arrows, forwardback arrows, colors, leaves, trees, and shoe-on-pedal. High matching agreement was recorded as seen in Table 4.

\subsubsection{Survey results}

As shown in Table 5, in the overall FE trial, the leaf icons and horizontal segmented bars were seen as least informative, most distracting, and least preferred. In the inform trial, the arch icons were reported as most informative, least distracting, and most preferred. The foot-to-pedal icons were most distracting while the up-down arrow icons were preferred in the instruct trial. In all other measures there were no clear participant preferences.

Frequencies were higher for instruct displays over inform displays across all three trials. Chi square binomial probability tests of responses showed that the inform icons had significantly greater ease of understanding $(p=0.024)$, were the least distracting $(p<0.001)$, and most preferred $(p<0.001)$.

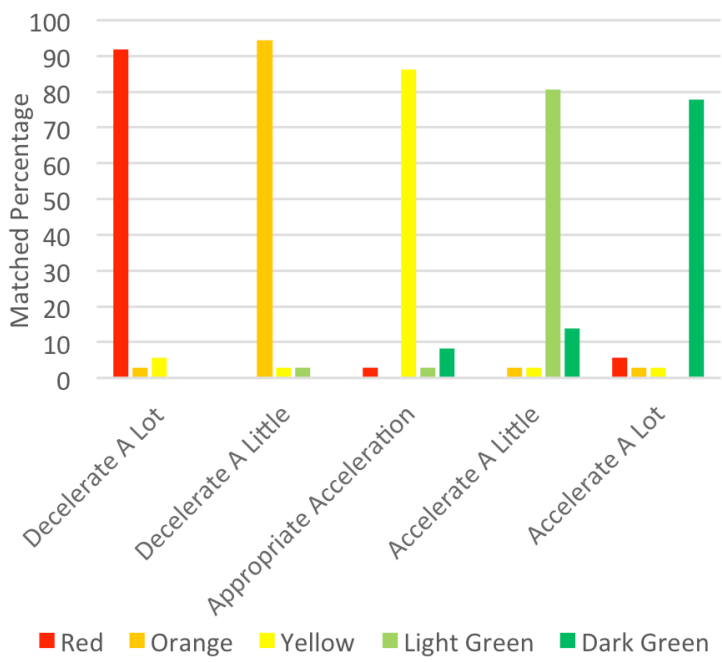

Figure 5: Match percentages of various colors from Experiment 2 instruct trial.

\begin{tabular}{|c|c|c|c|c|c|c|}
\hline Inform & Arches & $\begin{array}{c}\text { Vertical } \\
\text { seg. bars }\end{array}$ & \multicolumn{2}{|c|}{$\begin{array}{l}\text { Horizontal } \\
\text { seg. bars }\end{array}$} & $\begin{array}{c}\text { Vertical } \\
\text { cont. bars }\end{array}$ & $\begin{array}{l}\text { Horizontal } \\
\text { irs } \\
\text { cont. bars }\end{array}$ \\
\hline Most Informative & 25 & 6 & \multicolumn{2}{|c|}{10} & 1 & 2 \\
\hline Least Distracting & 21 & 8 & \multicolumn{2}{|c|}{6} & 4 & 5 \\
\hline Most Preferred & 28 & 6 & \multicolumn{2}{|c|}{5} & 1 & 4 \\
\hline Instruct & $\begin{array}{c}\text { Arrows } \\
\text { (up/down) }\end{array}$ & \multicolumn{2}{|c|}{$\begin{array}{c}\text { Arrows } \\
\text { (left/right) }\end{array}$} & \multicolumn{2}{|c|}{$\begin{array}{c}\text { Vertical seg. } \\
\text { bars }\end{array}$} & Foot \& Pedal \\
\hline Most Informative & 13 & \multicolumn{2}{|c|}{10} & \multicolumn{2}{|c|}{8} & 13 \\
\hline Least Distracting & 15 & \multicolumn{2}{|c|}{9} & \multicolumn{2}{|r|}{15} & 5 \\
\hline Most Preferred & 17 & \multicolumn{2}{|c|}{10} & \multicolumn{2}{|c|}{10} & 7 \\
\hline $\begin{array}{l}\text { Overall Eco- } \\
\text { Driving }\end{array}$ & Tree & \multicolumn{2}{|c|}{ Leaves } & \multicolumn{2}{|c|}{$\begin{array}{l}\text { Vertical seg. } \\
\text { bars }\end{array}$} & $\begin{array}{l}\text { Horizontal } \\
\text { seg. bars }\end{array}$ \\
\hline Most Informative & 16 & \multicolumn{2}{|c|}{9} & \multicolumn{2}{|c|}{16} & 4 \\
\hline Least Distracting & 12 & \multicolumn{2}{|c|}{5} & \multicolumn{2}{|r|}{19} & 9 \\
\hline Most Preferred & 15 & \multicolumn{2}{|c|}{8} & \multirow{2}{*}{\multicolumn{3}{|c|}{ Inform }} \\
\hline Instruct vs Inform & \multicolumn{3}{|c|}{ Instruct } & & & \\
\hline Ease of Use & \multicolumn{3}{|c|}{15} & \multicolumn{3}{|c|}{29} \\
\hline Least Distracting & \multicolumn{3}{|c|}{11} & \multicolumn{3}{|c|}{33} \\
\hline Preference & \multicolumn{3}{|c|}{9} & \multicolumn{3}{|c|}{35} \\
\hline
\end{tabular}

Table 5: Preference survey frequencies from Experiment 2. 


\section{GENERAL DISCUSSION}

The results of Experiments 1 and 2 comparing instruct and inform display types expose a potential hurdle for design. Acoustic parameters that matched to instruct icon-word pairs generally revealed an opposite polarity to those matched to inform icon-word pairs (Table 1). For example, in the instruct trial, participants matched ascending pitches to accelerate, and descending pitches to decelerate. In the inform trial, participants matched ascending pitches to excessive acceleration and descending pitches to insufficient acceleration. Here the polarities are opposite because instructing a driver to accelerate and informing a driver of insufficient acceleration is delivering information about the same driving phenomenon. However, these two analogous concepts were mapped to opposite acoustic parameters: ascending and descending frequencies, respectively. Decelerate and excessive acceleration (similar concepts) were also mapped to opposite acoustic parameters: descending and ascending, respectively. This may actually make it simpler to develop auditory interfaces for this task, as the designers do not have to worry about issues of cross coding of the displays.

The same pattern can be seen in the Experiment 2 iconto-concept matching results (Table 4). For example, a vertical bar in the up position matched best to accelerate, but was also matched to excessive acceleration. Similarly, a vertical bar in the down position matched best to decelerate, but was also matched to insufficient acceleration. The opposite polarities between inform and instruct displays could be problematic for a design, which draws from both. This issue must be considered in future multimodal displays.

Experiment 1 surveys found instruct auditory displays preferable, while Experiment 2 surveys found inform visual displays preferable (Hypothesis 1). However, a multimodal display using instruct sounds and inform visuals would present incongruent information with opposite polarities. This could lead to user confusion and distraction in the driving environment. These findings should also be used to advise future multimodal design.

\subsection{Human-centric and System-centric Displays}

Human-centric and system-centric displays are two approaches to showing information to drivers, whether it is information based on human parameters (human-centric), or system parameters (system-centric). In the current study both the instruct and inform displays were human-centric because they directly told the driver how to engage or change driving behavior or told them about their eco-driving behaviors, both of which were focused on the human. However, the overall FE information was a system-centric display as it displayed a metric describing the fuel economy within the system to the driver. These factors should be considered further in future work.

\subsection{Major findings and future research}

The purpose of this study was to find patterns and preferences that contribute to both an auditory and HUD design. Major findings include the high auditory and visual matching frequencies (Tables $1 \& 4$; Research Question $1 \&$ $2)$. These trends, along with survey results indicating preferences, directed our design of intuitive, usable, and unambiguous auditory and HUD FEDIs. Future research will evaluate how research-driven designs compare to commercially used visual dashboard displays. This next-step research will investigate these prototypes in a driving simulator study. The primary measures will include ecodriving behavior, eye behavior, subjective workload, and driving performance. Future research should also consider other age groups to ensure that matching of the displays does carry over age groups, or to determine what differences are seen between age groups. Results from these works could serve as a verification of the design guidance in this study and will help determine what types of displays effectively and safely communicate fuel efficiency to shape driver behavior.

\section{ACKNOWLEDGMENTS}

We would like to thank Brianna Tomlinson, Abhishek Sen, and Yiwei Hao for their help with the research. Portions of the work were supported by a National Science Foundation Graduate Research Fellowship (DGE-1148903) as well as additional grant funding from the NSF and from the National Institute on Disability, Independent Living, and Rehabilitation Research (NIDILRR).

\section{REFERENCES}

1. Staubach, M., Schebitz, N., Koster, F., \& Kuck, D. (2014). Evaluation of an eco-driving support system. Transportation Research Part F: Traffic Psychology and Behavior.

2. Nees, M. A., Gable, T., Jeon, M., \& Walker, B. N. (2014). Prototype auditory displays for a fuel efficiency driver interface. In 20th International Conference on Auditory Display.

3. Gonder, J., Earleywine M., \& Sparks, W. (2011). Final report on the fuel saving effectiveness of various driver feedback approaches. National Renewable Energy Laboratory.

4. Jamson, A., Hibberd, D., \& Merat, N. (2015). Interface design considerations for an in-vehicle eco-driving assistance system. Transportation Research Part C: Emerging Technologies.

5. Waard, D. (1996). The measurement of drivers' mental workload. Traffic Research Center: Groningen University.

6. Wickens, C. (2008). Multiple resources and mental workload. Human Factors, 6, 449-55.

7. Ralph, J., Gray, W. D., \& Schoelles, M. J. (2013) Cognitive Workload and the Motor Component of Visual Attention.

8. Tardieu, J., Misdariis, N., Langlois, S., Gaillard, P., \& Lemercier, C. (2015). Sonification of in-vehicle interface reduces gaze movements under dual-task condition. Applied ergonomics, 50, 41-49.

9. Gable, T. M., Walker, B. N., Moses, H. R., \& Chitloor, R. D. (2013, October). Advanced auditory cues on mobile phones help keep drivers' eyes on the road. In Proceedings of the 5th International Conference on Automotive User Interfaces and Interactive Vehicular Applications (pp. 66-73). ACM.

10. Jeon, M., Gable, T. M., Davison, B. K., Nees, M. A., Wilson, J., \& Walker, B. N. (2015). Menu navigation with in-vehicle technologies: Auditory menu cues improve dual task performance, preference, and workload. International Journal of Human-Computer Interaction, 31(1), 1-16. 
11. Lewis, B., \& Baldwin, C. (2015). Comparison of traditional psychophysical and sorting methods for invehicle display design. Proceedings of the Human Factors and Ergonomics Society 59th Annual Meeting.

12. Nees, M. A., \& Walker, B. N. (2011). Auditory displays for in-vehicle technologies. Reviews of human factors and ergonomics, 7(1), 58-99.

13. Wiese, E., \& Lee, J. D. (2001, October). Effects of multiple auditory alerts for in-vehicle information systems on driver attitudes and performance. In Proceedings of the Human Factors and Ergonomics Society Annual Meeting (Vol. 45, No. 23, pp. 16321636). SAGE Publications.

14. Young, M. S., Birrell, S. A., \& Stanton, N. A. (2011). Safe driving in a green world: A review of driver performance benchmarks and technologies to support 'smart' driving. Applied ergonomics, 42(4), 533-539.

15. Burns, P. C., Andersson, H., \& Ekfjorden, A. (2001). Placing visual displays in vehicles: where should they go? Internal Conference on Traffic and Transport. Psychology-ICTTP 4-7 September 2000.

16. Summala, H., Nieminen, T., \& Punto, M. (1996). Maintaining lane position with peripheral vision during in-vehicle tasks. Human Factors: The Journal of the Human Factors and Ergonomics Society, 38(3), 442451.

17. Wittmann, M., Kiss, M., Gugg, P., Steffen, A., Fink, M., Pöppel, E., \& Kamiya, H. (2006). Effects of display position of a visual in-vehicle task on simulated driving. Applied Ergonomics, 37(2), 187-199.

18. Liu, Y. C. (2003). Effects of using head-up display in automobile context on attention demand and driving performance. Displays, 24(4), 157-165.

19. Guastello, S. J. (2013). Human factors engineering and ergonomics: A systems approach. CRC Press.

20. Sanders, M. S. \& McCormick, E. J. (1993). Human Factors in Engineering and Design ( $7^{\text {th }}$ ed.). New York: McGraw-Hill.

21. Fors, C., Kircher, K., \& Ahlström, C. (2015). Interface design of eco-driving support systems- $\quad$ Truck drivers' preferences and behavioural compliance. Transportation Research Part C: Emerging Technologies, 58, 706-720.

22. Meschtscherjakov, A., Wilfinger, D., Scherndl, T., \& Tscheligi, M. (2009). Acceptance of future persuasive in-car interfaces towards a more economic driving behaviour. Proceedings of the 1st International Conference on Automotive User Interfaces and Interactive Vehicular Applications.

23. Tomlinson B., Schuett, J. H., Shortridge, W. H., \& Walker, B. N. (2016). "Talkin About the Weather": Incorporating TalkBack Functionality and Sonifications for Accessible App Design. In Mobile human-computer interaction-MobileHCI 2016 